\title{
O Processo Orçamentário de uma Instituição Pública Federal de Ensino sob a Ótica do Isomorfismo
}

\author{
Zambenedetti, Lidiane; Angonese, Rodrigo \\ O Processo Orçamentário de uma Instituição Pública Federal de Ensino sob a Ótica do Isomorfismo \\ Administração Pública e Gestão Social, vol. 12, núm. 2, 2020 \\ Universidade Federal de Viçosa, Brasil \\ Disponible en: http://www.redalyc.org/articulo.oa?id=351562414010
}

Esta obra está bajo una Licencia Creative Commons Atribución-NoComercial-SinDerivar 3.0 Internacional. 


\title{
O Processo Orçamentário de uma Instituição Pública Federal de Ensino sob a Ótica do Isomorfismo
}

\author{
The Budgetary Process of a Federal Public Institution of Education under the Isomorphism Optics \\ El Procedimiento Presupuestario de una Institución Pública Federal de Enseñanza Bajo la Óptica del Isomorfismo
}

Lidiane Zambenedetti

Instituto Federal do Rio Grande do Sul, Brasil

Redalyc: http://www.redalyc.org/articulo.oa?

lidiane.zambenedetti@erechim.ifrs.edu.br

Rodrigo Angonese

Universidade de Passo Fundo, Brasil

rangonese@gmail.com

Recepción: 19 Septiembre 2017

Aprobación: 15 Marzo 2019

Publicación: 01 Abril 2020

\section{Resumo:}

Esta pesquisa tem como objetivo analisar o processo orçamentário de uma instituição pública de ensino sob a ótica do isomorfismo. A proposta teórica e conceitual para o isomorfismo foi baseada em Dimaggio e Powell. Segundo o isomorfismo, as organizações tendem a se assemelhar, incluindo práticas de gestão, como é o caso do orçamento público. $\mathrm{O}$ entendimento do processo orçamentário permite possibilidade de aprimorá-lo, permitindo ganhos para as instituições e para a sociedade. A pesquisa, de caráter qualitativo e exploratório, adota a perspectiva da Teoria Institucional. O procedimento técnico foi o estudo de caso, realizado junto a uma instituição pública federal de ensino. A coleta dos dados ocorreu por meio de entrevistas, análise documental e observação participante junto a seis campi da instituição de ensino. Os resultados mostram que o processo orçamentário da instituição é influenciado pelos três tipos de isomorfismo (coercitivo, mimético e normativo). Observou-se que os três tipos de isomorfismo atuam simultaneamente, influenciando o processo orçamentário, com destaque para o isomorfismo coercitivo. $\mathrm{O}$ isomorfismo normativo é o menos explorado. A criação de um ambiente que potencialize o isomorfismo mimético, ou associações que permitam a defesa de interesses comuns, na perspectiva do isomorfismo normativo, estão entre algumas ações que podem aumentar a eficiência da gestão pública.

Palavras-Chave: Orçamento Público, Planejamento Público, Nova Sociologia Institucional, Gestão pública.

\section{ABstract:}

This research aims to analyze the budgetary process of a public institution of education from the point of view of isomorphism. The theoretical and conceptual proposal for isomorphism was based on Dimaggio and Powell. According to isomorphism, organizations tend to resemble each other, including management practices, such as the public budget. The understanding of the budget process allows the possibility of improving it, allowing gains for institutions and for society. The research, both qualitative and exploratory, adopts the perspective of Institutional Theory. The technical procedure was the case study, carried out in a federal public institution of education. Data were collected through interviews, documentary analysis and participant observation, along with six campuses of the educational institution. The results show that the institution's budget process is influenced by the three types of isomorphism (coercive, mimetic and normative). It was observed that the three types of isomorphism act simultaneously, influencing the budget process, with emphasis on coercive isomorphism. Normative isomorphism is the least explored. The creation of an environment that enhances the mimetic isomorphism, or associations that allow the defense of common interests, from the perspective of normative isomorphism are among some actions that can enhance the efficiency of public management.

KEYWORDS: Public Budget, Public Planning, New Institutional Sociology, Public administration.

\section{Resumen:}

Esta investigación tiene como objetivo analizar el proceso presupuestario de una institución pública de enseñanza bajo la óptica del isomorfismo. La propuesta teórica y conceptual para el isomorfismo se basó en Dimaggio y Powell. Según el isomorfismo, las organizaciones tienden a asemejarse, incluyendo prácticas de gestión, como es el caso del presupuesto público. El entendimiento del proceso presupuestario permite la posibilidad de perfeccionarlo, permitiendo ganancias para las instituciones y para la sociedad. 
La investigación, de carácter cualitativo y exploratorio, adopta la perspectiva de la Teoría Institucional. El procedimiento técnico fue el estudio de caso, realizado junto a una institución pública federal de enseñanza. La recolección de los datos ocurrió por medio de entrevistas, análisis documental y observación participante, junto a seis campus de la institución de enseñanza. Los resultados muestran que el proceso presupuestario de la institución está influenciado por los tres tipos de isomorfismo (coercitivo, mimético y normativo). Se observó que los tres tipos de isomorfismo actúan simultáneamente, influenciando el proceso presupuestario, con destaque para el isomorfismo coercitivo. El isomorfismo normativo es el menos explotado. La creación de un ambiente que potencie el isomorfismo mimético, o asociaciones que permitan la defensa de intereses comunes, en la perspectiva del isomorfismo normativo están entre algunas acciones que pueden aumentar la eficiencia de la gestión pública.

Palabras clave: Presupuesto Público, Planificación Pública, Nueva Sociología Institucional, Gestión pública.

\section{INTRODUÇÃO}

Tanto na área privada como na área pública, o orçamento é um instrumento de gestão necessário ao planejamento, à execução e ao controle, frequentemente objeto de pesquisas em diferentes áreas do conhecimento. Haja vista a importância atribuída a esse instrumento de gestão, esta pesquisa posiciona o orçamento como uma prática que está imersa em um contexto socioinstitucional. A partir dessa abordagem, obtém-se uma perspectiva teórica complementar àquelas predominantes.

Pesquisas que objetivam estudar o orçamento utilizam muitas abordagens teóricas e perspectivas, buscando sempre a melhor compreensão do fenômeno (Luft \& Shilds, 2003). Covaleski, Evans, Luft e Shields (2003) explicam que as pesquisas na área do controle gerencial com foco no orçamento seguem, geralmente, três perspectivas teóricas: A econômica, a psicológica e a sociológica. A perspectiva sociológica sobre orçamento refere-se às tradições de pesquisa sociológica e organizacional que se preocupam com questões orçamentárias dentro e entre as organizações. $O$ vínculo entre orçamento e política sugere que o orçamento não serve apenas para facilitar a tomada de decisão ou para identificar as melhores soluções no planejamento e controle de recursos. O orçamento também pode ser utilizado para facilitar os processos políticos e a pluralidade de interesses existentes em meio à vida organizacional complexa (Covaleski et al., 2003).

$\mathrm{Na}$ perspectiva da Teoria Institucional, os instrumentos de controle de gestão devem ser estudados sem dissociá-los do contexto socioinstitucional em que a organização está imersa. Além disso, sob a ótica da Teoria Institucional, as mudanças estruturais nas organizações estão cada vez menos preocupadas com a eficiência e com a competitividade, e sim com a necessidade de obter legitimidade no ambiente em que atuam (Meyer \& Rowan, 1977). A necessidade de legitimidade potencializa o processo de isomorfismo, que busca explicar os motivos que tornam as organizações similares (Meyer \& Rowan, 1977). Assim, o processo orçamentário pode sofrer influência do isomorfismo, que é o conceito utilizado para descrever a homogeneização das organizações. Conforme Hawley (1968), o isomorfismo é um processo que força uma unidade a assemelharse a outra devido ao fato de pertencerem a um mesmo conjunto de condições ambientais. Dimaggio e Powell (1983) apresentam três tipos de isomorfismo: Isomorfismo coercitivo, isomorfismo mimético e isomorfismo normativo.

O isomorfismo coercitivo relaciona-se à influência política e ao problema de legitimidade e, nesse caso, as mudanças ocorrem por imposição. O isomorfismo mimético está relacionado ao fato de que as organizações tenderão a modelar-se conforme outras organizações (Dimaggio \& Powell, 1983). Já o isomorfismo normativo refere-se à ligação das organizações com a profissionalização e encoraja a homogeneização das organizações, objetivando assegurar o fornecimento dos mesmos benefícios e serviços para todos os competidores (Dimaggio \& Powell, 1983).

Diante do contexto exposto, este estudo procura responder à seguinte pergunta de pesquisa: Como o processo orçamentário de uma instituição pública de ensino pode ser explicado pelo isomorfismo? Assim, tem como objetivo analisar o processo orçamentário de uma instituição pública de ensino sob a ótica do isomorfismo segundo Dimaggio e Powell (1983). O pressuposto da investigação institui que o processo 
orçamentário de uma instituição pública de ensino é influenciado pelos três tipos de isomorfismo, segundo Dimaggio e Powell (1983), em conformidade com a nova sociologia institucional.

A relevância desta pesquisa deve-se ao fato de a perspectiva institucional oferecer inovação às pesquisas na área de controle de gestão, pois ela é estudada como sendo uma implicação da construção social da realidade, em vez de refletir passivamente a realidade (Covaleski, Dirsmith, \& Samuel, 1996). Para a teoria, esta pesquisa espera contribuir explorando a dimensão sociológica que envolve a ferramenta do orçamento público, estudado como um instrumento de controle gerencial. Pesquisas que mostram o avanço de estudos através desta visão ampliam a maneira com que o fenômeno é observado.

Esta pesquisa se desenvolve considerando o contexto de uma instituição pública federal de ensino e justifica-se tendo em vista que essas instituições têm por missão promover o acesso à educação pública de qualidade, o que fomenta o desenvolvimento com melhor distribuição da renda e a diminuição da desigualdade social (Saviani, 2015). Segundo o autor, o acesso à educação impacta positivamente no desenvolvimento econômico do país, trazendo oportunidade de emprego, inclusão social, resolução dos problemas sócio-econômicos. Portanto, a contribuição prática da pesquisa reside na ampliação da compressão da relação entre o isomorfismo e o processo orçamentário. Isso permite aos gestores respostas que expliquem e norteiem a prática orçamentária. Quando a gestão está ciente de como as práticas gerenciais são instituídas, há a possibilidade de ganhos de eficiência, seja pela implementação ou aprimoramento das práticas em uso.

Esta pesquisa foi operacionalizada a partir de um estudo de caso realizado junto a seis campi de uma instituição federal de ensino. A partir da análise de dados obtidos por entrevistas, análise documental e observação, contatou-se que o processo orçamentário apresenta influência dos três tipos de processos orçamentários segundo Dimaggio e Powell (1983). Pode-se entender que o processo orçamentário público está regulado por normas legais, caracterizando apenas o isomorfismo coercitivo. Entretanto, normas legais direcionam o processo orçamentário ao mesmo tempo em que garantem liberdade administrativa para que as instituições públicas gerenciem os recursos orçamentários. Esta pesquisa mostra que o isomorfismo mimético e o normativo também encontram-se presentes no processo orçamentário. A presença dos três tipos de isomorfismo no processo orçamentário constitui-se em uma das principais contribuiçóes da pesquisa, compreensão que permite oportunidade de ganhos de eficiência e aprimoramento da gestão pública.

\section{FUNDAMENTAÇÃO TEÓRICA}

\subsection{O orçamento sob a ótica da Teoria Institucional}

Muitos estudos, como os de Abdel-Kader e Luther (2006), Sivabalan, Booth, Malmi e Brown (2009), Libby e Lindsay (2010), Ostergren e Stensaker (2011), Uyar e Bilgin (2011), apontam o orçamento como um dos instrumentos mais utilizados no planejamento e controle das organizações. O orçamento é um subconjunto do sistema de controle gerencial e, portanto, não deve ser planejado de maneira isolada.

Giacomoni (2005) explica que o orçamento público é uma técnica utilizada com o objetivo de unir os sistemas de planejamento e de finanças dos programas de governo. $\mathrm{O}$ gestor público deve pensar e agir estrategicamente, com uma visão futura voltada para o progresso e a melhoria da qualidade de vida da sociedade, a quem são destinadas as ações do planejamento e orçamento público (Cruz, 2001).

Conforme Xerez (2013), o orçamento público é uma ferramenta que auxilia a tomada de decisão dos gestores, atuando como um instrumento de planejamento do controle das finanças, demonstrando os planos e programas de trabalho da gestão. No orçamento constam a previsão das receitas e a fixação das despesas. Sendo assim, a correta alocação e a eficiente utilização dos recursos tornam-se fundamentais para o alcance do planejamento e do desenvolvimento empreendidos (Quirino, 2011). 
Para Covaleski et al. (2003), o orçamento, na maioria das vezes, é estudado através da perspectiva econômica, a qual o considera como um componente do sistema de controle gerencial, que desempenha importante papel para coordenar atividades e para prover incentivos nas organizações. Através dessa perspectiva são analisadas as escolhas orçamentárias e os resultados produzidos por elas que resultam em bem-estar individual e desempenho organizacional (Covaleski et al., 2003). Porém, o orçamento pode ser investigado através de diversas perspectivas (Luft \& Shields, 2003). Covaleski et al. (2003) salientam que, na área do controle gerencial, o orçamento pode ser estudado através das perspectivas econômica, psicológica e sociológica. A perspectiva sociológica, utilizada nesta pesquisa, refere-se às tradições de pesquisa sociológica e organizacional que se preocupam com questões orçamentárias dentro e entre as organizações (Covaleski et al., 2003).

No tocante à contabilidade, Pereira e Guerreiro (2005) explicam que a Teoria Institucional considera a contabilidade gerencial como uma instituição ou rotina dentro da empresa, a qual é amplamente aceita de forma inquestionável. A Teoria Institucional objetiva encontrar explicações sobre os motivos de as instituições surgirem, tornarem-se estáveis ou transformadas e como são estruturadas suas formas e culturas (Freitas, 2005). Conforme Fonseca e Machado-da-Silva (2002), pesquisadores que utilizam a abordagem institucional consideram que o comportamento individual é modelado por padróes criados e compartilhados durante a interação dos indivíduos, apresentados como a maneira mais eficaz de funcionamento das organizações. Burns e Scapens (2000) utilizam conceitos de hábitos, rotinas e instituições para sugerir como as práticas contábeis podem tornar-se rotinizadas e através do tempo começar a fazer parte do conjunto das pressuposições e crenças inquestionáveis da organização. Estes autores ainda afirmam que a Teoria Institucional é abordada através de três expectativas: A velha economia institucional, a nova economia institucional e a nova sociologia institucional. Esta pesquisa será desenvolvida através da expectativa da nova sociologia institucional.

A nova sociologia institucional considera que as organizações sofrem pressões do ambiente em que estão inseridas e isso estaria diretamente relacionado à aceitação dos procedimentos que já estão institucionalizados. Quando a organização institucionaliza os procedimentos, ela passa a legitimar-se perante o ambiente e isso auxilia sua sobrevivência e obtenção de recursos (Meyer \& Rowan, 1977; Covaleski et al., 2003). Ribeiro e Scapens (2006) conceituam institucionalização como sendo convenções que governam a vida social e que explicam a regularidade dos fatos.

Os principais autores desta vertente são Dimaggio e Powell (1983), Meyer e Rowan (1977), Scott (1995) e Zucker (1977). Para Guerreiro, Pereira e Frezatti (2006), o foco é as organizações configuradas em uma grande rede de relacionamentos interorganizacionais e sistemas culturais. $\mathrm{O}$ entendimento dos autores é de que o ambiente institucional não influencia apenas o relacionamento entre as organizações e o mercado, mas também suas crenças, normas e tradições. Para eles, os indivíduos e organizações precisam conformar-se a regras, práticas, símbolos, crenças e requerimentos normativos elaborados no ambiente institucional para receber apoio e legitimidade. Segundo Covaleski et al. (1996), o tema geral dessa perspectiva considera que, para assegurar a sua sobrevivência, a organização precisa conformar-se às normas sociais de comportamento aceitável, além de atingir níveis de eficiência produtiva.

\subsection{Isomorfismo com base em Dimaggio e Powell (1983)}

A Teoria Institucional, na vertente da Nova Sociologia Institucional, contempla três tipos de mecanismos isomórficos no processo de institucionalização: Isomorfismo coercitivo, isomorfismo mimético e isomorfismo normativo (Dimaggio \& Powell, 1983). A Tabela 1 apresenta um resumo sobre esses tipos de isomorfismo. 
Tabela 1 Tipos de isomorfismo

\begin{tabular}{|c|c|}
\hline Isomorfismo & Descrição \\
\hline Coercitivo & $\begin{array}{l}\text { Está diretamente relacionado à influência política e à legitimidade. Resulta } \\
\text { de pressões formais e informais. As mudanças podem ocorrer por força de } \\
\text { lei. }\end{array}$ \\
\hline Mimético & $\begin{array}{l}\text { As organizaçốes tendem a modelar-se como outras organizações quando o } \\
\text { ambiente cria uma incerteza, quando os objetivos são ambiguos ou até } \\
\text { mesmo frente a tecnologias não tão bem compreendidas. }\end{array}$ \\
\hline Normativo & $\begin{array}{l}\text { Refere-se à ligação das organizações com a profissionalização. As } \\
\text { organizações que atuam no mercado enfrentam pressões constantes pelo } \\
\text { aumento da eficiência competitiva e, por isso, o isomor fismo normativo } \\
\text { encoraja a homogeneizaçâo das organizaçôes, com o objetivo de assegurar } \\
\text { o fornecimento dos mesmos benefícios e serviços para todos os } \\
\text { competidores. }\end{array}$ \\
\hline
\end{tabular}

Fonte: Adaptado de Dimaggio, P. J., \& Powell, W. W. (1983). The Iron Cage Revisited: Institutional Isomorphism and Collective Rationality in Organizational Fields. American Sociological Review, 48, 147-160.

Conforme a Tabela 1, o isomorfismo coercitivo está diretamente relacionado à influência política e à legitimidade. Resulta de pressões formais e informais, exercidas em organizações que são dependentes de outras e também através das expectativas culturais da sociedade. Essa pressão tem por objetivo forçar, persuadir para entrar em conformidade. Nesse tipo de isomorfismo as mudanças podem ocorrer por força de lei, pois o ambiente legal afeta diretamente o comportamento e a estrutura da organização. Os autores ainda afirmam que esse tipo de isomorfismo não ocorre somente por imposição do governo, mas também por imposições da matriz às suas filiais, exigindo padronização de estruturas, métodos, filosofias e comportamentos (Dimaggio \& Powell, 1983).

$\mathrm{O}$ isomorfismo mimético relaciona a presença da incerteza como uma força que conduz ao isomorfismo. Nesse contexto, as organizações tendem a modelar-se como outras organizações quando o ambiente cria uma incerteza, ou quando os objetivos são ambíguos ou até mesmo frente a tecnologias não tão bem compreendidas. Como vantagem, as organizações que praticam esse tipo de isomorfismo conseguem gerar certa economia na busca de soluções, pois, ao imitar um procedimento que já está em uso, a organização subentende que o procedimento já foi avaliado e pensado para a solução do problema (Dimaggio \& Powell, 1983).

O isomorfismo normativo refere-se à ligação das organizações com a profissionalização. Conforme Larson (1977) e Collins (1979), a profissionalização é caracterizada pelo esforço coletivo dos membros de um determinado grupo em definir as condições e os métodos do seu trabalho. Conforme Dimaggio e Powell (1983), essas fontes de profissionalização são encontradas em cursos superiores, que oferecem educação formal e legitimidade em uma base cognitiva produzida por meio de especialistas, e também em redes profissionais que desenvolvem normas organizacionais sobre o comportamento organizacional e profissional. Dimaggio e Powell (1983) ainda consideram que as organizações que atuam no mercado enfrentam pressões constantes pelo aumento da eficiência competitiva e, por isso, o isomorfismo normativo encoraja a homogeneização das organizações, com o objetivo de assegurar o fornecimento dos mesmos benefícios e serviços para todos os competidores.

\subsection{Isomorfismo e organizações}

Compreender os mecanismos do isomorfismo auxilia no entendimento das mudanças organizacionais e suas dinâmicas (Machado-da-Silva \& Barbosa, 2002). O setor público está sempre sujeito às influências políticas e pressões constantes para atender um ou outro padrão institucionalizado. Para eles, a Constituição Federal de 1988 é o ordenamento jurídico seminal para que práticas gerenciais chegassem à realidade da administração 
pública brasileira e, consequentemente, às instituições federais de ensino brasileiras, seguidas por tantas outras legislações que disciplinassem sua implementação. A homogeneização geralmente é imposta, dentre outros motivos, pelas regulamentações de órgãos fiscalizadores governamentais (Baêta, Sousa, Antonialli, \& Cappelle, 2014).

Coser e Machado-da-Silva (2004) citam como exemplo de isomorfismo coercitivo o Governo, que determina leis que devem ser cumpridas pelas organizações, ou uma grande organização que impõe regras às demais. Outro exemplo é trazido por Diniz, Mesquita, Tassigny e Assis (2015), os quais classificam a regulamentação hegemônica das instituições que devem se submeter à legislação exigida pelo Ministério da Educação (MEC) como isomorfismo coercitivo.

Há de se considerar também que tanto na área pública quanto na área privada, o isomorfismo pode ocorrer devido ao fato de formas não satisfatórias serem excluídas de uma população de organizações ou porque os responsáveis pela tomada de decisão nas organizações aprenderam respostas adequadas e ajustaram seu comportamento a elas (Machado-da-Silva \& Fonseca, 1993). Assim, há espaço para outras formas de isomorfismo, como o mimético ou o normativo.

O isomorfismo mimético se processa na adoção, por parte de determinada organização ou grupo, de procedimentos e arranjos estruturais implementados por outras organizaçóes ou grupos com a finalidade de reduzir a incerteza ocasionada por problemas tecnológicos, objetivos conflitantes e exigências institucionais (Machado-da-Silva \& Vizeu, 2007). Um dos motivos que faz com que uma organização adote postura isomórfica é a autodefesa frente a situações sem soluções geradas internamente, uma vez que a semelhança facilita as transações interorganizacionais (Machado-da-Silva \& Fonseca, 1993). Conforme Pacheco (2002), a sobrevivência de uma organização depende da sua capacidade de manter um ajuste permanente entre as pressões de legitimidade. Para a autora, essas pressões são impostas pelo ambiente institucional, através de normas e costumes socialmente aceitos e, também, pela constante exigência de eficiência e eficácia. Ela explica que a falta desse ajuste pode ter como consequência uma conflituosa relação entre eficiência e legitimidade.

\section{MÉTODO}

Esta pesquisa apresenta uma abordagem interpretativista. Uma pesquisa interpretativista desenvolve-se considerando as crenças e práticas sociais. Nessa perspectiva, inclui-se a contabilidade gerencial, e, por conseguinte o orçamento, pois ela não é vista como um fenômeno natural, e sim socialmente construída. Esta abordagem procura por regras implícitas e explícitas, que explicam o comportamento social e não por leis universais ou generalizações (Ryan, Scapens, \& Theobald, 2002).

Trata-se de uma pesquisa qualitativa e exploratória, operacionalizada pelo procedimento técnico estudo de caso. $\mathrm{O}$ estudo de caso foi desenvolvido junto a uma instituição de ensino superior pública. A instituição de ensino superior foi selecionada intencionalmente (Eisenhardt, 1989), por questões de acessibilidade. Cabe destacar também que um dos pesquisadores constitui parte do corpo de servidores da instituição, fato que facilitou a participação dos sujeitos e viabilização da realização da pesquisa.

A instituição atua com uma estrutura composta por 17 campi e sua Reitoria. A pesquisa foi aplicada em seis campi da instituição. Optou-se por seguir as recomendações de Scapens (1990), que, no momento da seleção dos casos, afirma ser apropriado selecionar casos extremos, tendo em vista a possibilidade de ampliação da análise dos resultados. Para tanto foram selecionados os três maiores e os três menores campi para a realização desta pesquisa. O tamanho dos campi foi medido através de sua estrutura e número de alunos, uma vez que isto impacta diretamente no valor do orçamento anual. Na Tabela 2 são caracterizados os campi selecionados para a pesquisa. 
Tabela 2 Caracterização dos campi

$\begin{array}{ll}\text { Campus } & \begin{array}{l}\text { Tempo de } \\ \text { funcionamento } \\ \text { (anos) }\end{array} \\ \text { A } & 59 \\ \text { B } & 52 \\ \text { C } & 57 \\ \text { D } & 3 \\ \text { E } & 3 \\ \text { F } & 2 \\ \text { Reitoria } & 6\end{array}$

$\begin{array}{ll}\begin{array}{l}\text { Orçamento } \\ \text { 2016(R\$) }\end{array} & \begin{array}{l}\text { Número de } \\ \text { alunos }\end{array} \\ 9.479 .801,00 & 1.450 \\ 7.266 .542,00 & 1.470 \\ 6.284 .199,99 & 1.600 \\ 1.655 .636,00 & 200 \\ 820.895,00 & 100 \\ 412.811,00 & 62 \\ 8.438 .430,00 & -\end{array}$

$\begin{aligned} & \text { Número de } \\ & \text { servidores }\end{aligned}$
184
188
198
29
23
12
145

Estrutura

$\left(\mathrm{m}^{2}\right)$

$23.000,00$

$15.279,00$

$24.502,25$

$7.280,00$

$4.800,00$

$2.493,00$

$3.724,60$

Fonte: Dados da pesquisa (2016).

$\mathrm{Na}$ Tabela 2 pode-se observar que o campus mais antigo apresenta o maior orçamento da Instituição. Os Campi A e C incorporaram antigos Centros Federais de Educação Tecnológica e atualmente possuem 1.450 e 1.600 alunos respectivamente. $\mathrm{O}$ segundo maior orçamento pertence ao Campus $\mathrm{B}$, o qual incorporou o antigo Colégio Técnico Industrial ligado a uma Universidade Federal. Os três menores orçamentos são representados pelos Campi D, E e F, sendo que todos fazem parte do grupo de campi em implantação, com menos de 5 anos de funcionamento. Percebe-se que as características mostradas na Tabela 2 qualificam os casos como de características extremas, adequados para enriquecer as considerações da pesquisa (Scapens, 1990; Yin, 2016).

A coleta de dados envolveu entrevistas semiestruturadas junto aos servidores da instituição cujas atividades estivessem diretamente relacionadas ao processo de planejamento, execução e controle do orçamento. Foram entrevistados servidores que ocupam os seguintes cargos: Responsável pela execução orçamentária e financeira, contador, diretor administrativo, coordenador de desenvolvimento institucional, diretor-geral, pró-reitor de administração e reitor. No total, foram realizadas 31 entrevistas.

Houve um estudo de caso piloto, momento em que também foi realizado o pré-teste do roteiro de entrevista, com o objetivo de identificar a melhor forma de aplicação do instrumento, verificar a adequação do conteúdo e identificar problemas que poderiam interferir na fidedignidade dos dados. A análise do pré-teste trouxe evidências de que eram necessárias algumas alterações no roteiro de entrevista, tendo sido excluídas algumas questões, outras modificadas, e novas foram incluídas. As entrevistas foram realizadas no período de julho a setembro de 2016. Com a finalidade de garantir a confiabilidade dos dados, as entrevistas foram gravadas, com autorização prévia dos entrevistados. Posteriormente, o conteúdo foi transcrito e submetido à validação dos entrevistados.

Além das entrevistas, este estudo utilizou-se da observação participante e análise documental como técnicas de coleta de dados. A análise de documentos envolveu relatórios extraídos do Sistema Integrado de Administração Financeira do Governo Federal, editais de licitações, matriz orçamentária anual, planilhas auxiliares utilizadas para o planejamento da distribuição interna de recursos, atas de reunióes em que foram tratados assuntos sobre o orçamento. Esses documentos foram escolhidos com base na experiência de um dos pesquisadores, levando em conta o a disponibilidade e potencial que os mesmos ofereciam para a coleta dos dados.

A observação foi classificada como participante. Um dos pesquisadores caracterizou-se como observador participante revelado. Nessa condição, participou de eventos e situações, vivenciou a realidade constituindose como parte do contexto observado. Destaca-se que, como em qualquer outro contexto semelhante, a limitação dessa técnica de coleta de dados envolve o viés sociocultural do observador, o viés profissionalideológico, que induz à seletividade da observação, bem como vieses decorrentes de relacionamento interpessoal, emocional e normativo (Martins \& Theóphilo, 2007). 
Para a análise dos resultados foi utilizada a técnica de análise de conteúdo, conforme Bardin (2009). Para auxiliar na análise dos dados foi utilizado o software Atlas Ti, que permite a descoberta de fenômenos complexos, os quais possivelmente não seriam detectáveis na simples leitura do texto, principalmente em relação à técnica tradicional de tratamento dos dados manualmente (Queiroz \& Cavalcante, 2001). A análise de dados contemplou a definição de uma categoria de análise denominada Isomorfismo. Outras três subcategorias de análise foram definidas, denominadas de Isomorfismo Coercitivo, Mimético e Normativo.

Em atenção aos pressupostos ética da pesquisa, antes de dar início à coleta de dados, o projeto foi submetido ao Comitê de Ética em Pesquisa. Todos os entrevistados assinaram e receberam cópia do Termo de Consentimento Livre e Esclarecido (TCLE).

\section{RESULTADOS}

\subsection{Isomorfismo coercitivo}

Nesta seção, serão descritos os elementos coletados através de entrevistas, análise documental e de observação, que caracterizam a subcategoria de análise denominada isomorfismo coercitivo. Trechos de entrevista, documento da instituição, normativa, regimento, anotações de diário de campo são exemplos de elementos. Quando alinhados à definição constitutiva da subcategoria de análise, constituíram indício permitindo resultados na busca do objetivo proposto.

A Instrução Normativa 01/2016 - Instituto Federal (IF) é o primeiro elemento que caracteriza a existência de isomorfismo coercitivo. Ela apresenta os princípios que devem ser seguidos para a construção do Plano de Ação, buscando a homogeneização da forma como esse planejamento deverá ser construído, apresentando inclusive os passos e responsáveis de cada fase do Plano de Ação. A imposição de regulamentação formalizada dentro da própria organização constitui isomorfismo coercitivo (Dimaggio \& Powell, 1983).

Outro elemento que caracteriza o isomorfismo coercitivo são resoluções utilizadas para a distribuição de recursos entre as ações de capacitação, ensino, pesquisa e extensão. Essas resoluções buscam a homogeneização da distribuição de recursos para tais ações entre os campi que compõem a rede. Todos os entrevistados citaram a necessidade de observá-las durante a distribuição interna de recursos. A Resolução 114/14 trata do percentual mínimo (5\%) que deve ser destinado para a capacitação dos servidores, a Resolução 18/15 trata do percentual mínimo (1,5\%) que deve ser destinado ao Programa Institucional de Bolsas de Extensão (PIBEX), a Resolução $22 / 15$ prevê a destinação de 1,5\% para o Programa Institucional de Bolsas de Ensino (PIBEN) e, por fim, a Resolução 32/15 prevê a destinação de 1,5\% para Auxílio Institucional de Incentivo a Produção Científica e (ou) Tecnológica (AIPCT).

O isomorfismo coercitivo também é caracterizado quando a servidora R2 cita a necessidade de todos os campi seguirem o que está previsto no Plano de Desenvolvimento Institucional (PDI):

Nós temos o PDI que é o planejamento de médio prazo. [...] O PDI é lei, tem o dispositivo legal para as instituições federais de ensino. O PDI para os IFs é discutido no fórum dos pró-reitores de desenvolvimento institucional e o ponto positivo é que ele começou a ser planejado junto com a criação dos IFs, então sempre tem a mesma validade que uma gestão do reitor (R2).

A comprovação desta exigência foi observada no PDI 2014-2018, como se constata no seguinte trecho:

As ações a serem planejadas e executadas anualmente devem seguir as definições estabelecidas no PDI. Em especial, as ações devem ser planejadas para que se consiga, no longo prazo, atingir os objetivos e metas definidos neste plano. As ações, de forma mais detalhada, serão planejadas, no curto prazo, através dos planos de ações anuais, que devem utilizar este documento como base. O processo de acompanhamento do plano será realizado anualmente, com base na verificação dos objetivos e das metas que foram atingidas no período de avaliação. 
Ainda, com o objetivo de confirmar a imposição legal do PDI, realizou-se uma pesquisa no site da instituição, através da qual se constatou que ele é uma exigência do Decreto 5.773/2006:

\begin{abstract}
A elaboração do PDI das instituições de ensino superior é uma exigência, conforme o Decreto nº 5.773, de maio de 2006. Ele estabelece o PDI como um dos requisitos para o credenciamento das instituiçóes junto ao MEC. O Artigo 16 do Decreto 5.773/06 apresenta os elementos mínimos que devem estar contidos no PDI: Missão, objetivos e metas, histórico de implantação e desenvolvimento, PPI, cronogramas, organização didático-pedagógica, perfil de pessoal, dentre outros itens. Dentre as Diretrizes para a Elaboração do PDI apresentadas no documento do Fórum de Desenvolvimento Institucional, podem ser citados os documentos: Plano Nacional de Educação, naquilo que diz respeito às atividades fins dos Institutos Federais de Educação, Ciência e Tecnologia; Plano Plurianual; Lei de Diretrizes e Bases da Educação; Lei de criação dos IF; Diretrizes e Concepções dos IF; Relatórios de avaliação institucional (CPA) e Plano de Desenvolvimento Institucional 2009-2013.
\end{abstract}

Também, a necessidade de todos os campi precisarem aguardar a aprovação da matriz Conselho Nacional das Instituições da Rede Federal de Educação Profissional, Científica e Tecnológica (Conif), bem como a Lei Orçamentária Anual (LOA), para, finalmente, terem o conhecimento de quais serão os valores orçamentários disponíveis para o orçamento, também é elemento que está alinhado à definição constitutiva da subcategoria isomorfismo. Além disso, frente aos contingenciamentos que vêm ocorrendo de maneira coerciva nos últimos anos, todos os campi necessitam realizar ajustes em busca de adequarem suas necessidades aos recursos disponíveis. Por fim, a necessidade de consulta à comunidade para a construção do orçamento anual também é uma exigência legal, prevista do PDI 2014-2018.

\title{
4.2 Isomorfismo mimético
}

Em relação aos elementos coletados relacionadas ao isomorfismo mimético, observou-se que frente ao momento de incerteza que toda a rede federal de educação enfrenta, os campi objetos de estudo desta análise buscam maneiras semelhantes para solucionar seus problemas orçamentários. Conforme relatos dos entrevistados, assim como ocorreu em outros momentos de escassez de recursos, os gestores de cada campus então buscando verbas orçamentárias através de emendas parlamentares, com o auxílio de parlamentares influentes. Além dos projetos submetidos em separado pelos campi, um dos entrevistados apontou a necessidade da união de toda a rede em busca de recursos que sejam capazes de suprir suas necessidades. Outro meio utilizado para conseguir recursos extraorçamentários é a solicitação através de Termos de Execução Descentralizada (TEDs). Os entrevistados explicaram que, em momentos em que existem necessidades orçamentárias urgentes, vêm realizando solicitação de recursos por meio desses termos.

Ainda em meio à incerteza, servidores que estão atuando em cargos de gestão e que ainda não possuem experiências de como deve ocorrer o planejamento orçamentário explicaram que buscam conhecer os meios pelos quais outros campi realizam seu planejamento, desde ferramentas utilizadas para coletar necessidades da comunidade acadêmica, até necessidades orçamentárias que cada área pode apresentar. Cabe ressaltar que, muito embora o processo orçamentário seja regulado legalmente, há autonomia administrativa na gestão dos recursos, momento em que o isomorfismo mimético pode ser caracterizado. Isto se conforma a partir de relatos como "sim, foi utilizada a maneira com que o Campus 'X' planejava” (servidor B3); “lá eles já têm critérios bem consolidados, eu trabalhava lá anteriormente" (servidor D2); "Troquei uma ideia com um colega de outro campus, conheci ele em uma viagem e conversamos" (servidor E1), e "a gente trocou uma ideia lá, pois tínhamos metas em comum" (servidor E3).

Essa troca de informações influencia também na forma como o orçamento é inicialmente planejado. Praticamente todos os gestores informaram que utilizam como base para o planejamento do próximo exercício o orçamento do ano anterior, aplicando-lhe um percentual de reajuste. Apenas um dos entrevistados afirmou que realiza o planejamento base-zero, sem considerar valores anteriores. 
Outro indício da existência de isomorfismo mimético é observado no momento em que os gestores tomaram conhecimento do percentual que seria contingenciado para o próximo exercício. Gestores que já haviam atuado no planejamento orçamentário em anos anteriores tinham a experiência de que, na maioria das vezes, os recursos de investimento são os que sofrem maiores cortes. Sendo assim, mesmo sendo o principal recurso para colocar em funcionamento os campi em implantação, foi decidido que todos iriam prever recursos apenas de custeio, em busca de garantir o recebimento do maior volume possível do orçamento de 2017. No entendimento dos servidores que atuam nos campi em implantação, é melhor priorizar a manutenção das ações básicas da instituição do que prever recursos que podem, posteriormente, não ser liberados.

\subsection{Isomorfismo normativo}

O único elemento relacionado ao isomorfismo normativo foi obtido no depoimento do servidor E1, o qual explicou que, em experiência anterior como diretor de um campus pertencente a outra rede, existia a Associação dos Dirigentes dos Institutos Federais do Rio Grande do Sul. Conforme E1, as emendas parlamentares eram solicitadas de maneira coletiva, não beneficiando apenas uma unidade, mas distribuindo o recurso entre todas as unidades participantes.

\subsection{Discussão dos resultados}

Os tipos de isomorfismo, coercitivo, mimético e normativo, foram estudados a partir dos conceitos de Dimaggio e Powell (1983). Em relação ao isomorfismo coercitivo, os autores afirmam que está diretamente relacionado à influência política e à legitimidade. Explicam que é resultado de pressões formais e informais. Neste caso, as mudanças podem ocorrer por força de lei.

A caracterização da existência de isomorfismo coercitivo na instituição pesquisada foi configurada pela existência de instruções normativas e resoluções internas. Esses elementos internos de normatização buscam a homogeneização do Plano de Ação e, também, a equidade na distribuição de recursos para atenderem às ações de capacitação, ensino, pesquisa e extensão. Outro elemento que se destaca é a exigência de todos os campi seguirem o Decreto 5.773/2006, que dispõe sobre o exercício das funções de regulação, supervisão e avaliação de instituições de educação superior e cursos superiores de graduação e sequenciais no sistema federal de ensino. Conforme o Decreto, o Plano de Desenvolvimento Institucional é um requisito básico para o credenciamento de uma instituição de ensino junto ao MEC. Normatização implementada pelo governo pode ser citada como um exemplo de isomorfismo coercitivo, pois é responsável pela determinação de leis (Coser \& Machado-Da-Silva, 2004). Em relação às instituições de ensino, a regulamentação detém hegemonia sobre as instituições, que devem se submeter à legislação exigida pelo MEC, caracterizando-se essa homogeneidade como isomorfismo coercitivo (Diniz et al., 2015).

Baêta et al. (2014) explicam que o setor público está sempre sujeito às influências políticas e pressões constantes para atender um ou outro padrão institucionalizado. Para eles, a Constituição Federal de 1988 é o ordenamento jurídico seminal para que práticas gerenciais chegassem à realidade da administração pública brasileira e, consequentemente, as instituições federais de ensino brasileiras seguidas por tantas outras legislações que disciplinassem sua implementação. Eles afirmam ainda que a homogeneização é imposta, dentre outros motivos, pelas regulamentações de órgãos fiscalizadores governamentais.

Outro elemento importante encontrado na pesquisa e que caracteriza o isomorfismo coercitivo é a necessidade de todos os campi aguardarem a aprovação da matriz Conif para, finalmente, terem o conhecimento do real valor orçamentário que será disponibilizado no exercício seguinte. Assim como nesta pesquisa, Silva e Teixeira (2016) apontam a existência do isomorfismo coercitivo em um instituto federal, 
citando como exemplo as exigências do MEC em cumprir a missão de compreender a região no qual está inserido.

Em relação ao isomorfismo mimético, Dimaggio e Powell (1983) entendem que este ocorre devido ao fato de as organizações apresentarem uma tendência de se modelarem como outras organizações quando o ambiente cria uma incerteza ou quando os objetivos são ambíguos, ou até mesmo frente a tecnologias não tão bem compreendidas. Durante o relato dos entrevistados, ficou evidente que os diferentes campi buscam assemelhar-se para enfrentarem o momento de incerteza que toda a rede federal de educação vem enfrentando.

Dentre os elementos que viabilizam a explicação do processo orçamentário pelo mimetismo, é possível citar a busca por recursos extraorçamentários através de emendas parlamentares, a utilização de Termos de Execução Descentralizada, a troca de ideias em relação ao planejamento orçamentário entre servidores inexperientes e servidores mais antigos, o uso de dados relacionados ao ano anterior para serem tomados como base para o planejamento do próximo exercício, bem como a decisão de priorizar os recursos de custeio em detrimento do investimento frente ao contingenciamento anunciado pelo governo.

Aliado a esses achados, Silva e Teixeira (2016) também citam a internalização e o uso do planejamento nas instituições de ensino como um processo de isomorfismo mimético. Portanto, os achados desta pesquisa estão alinhados com os apontamentos de Machado-da-Silva e Vizeu (2007) quando mencionam que o isomorfismo mimético se processa na adoção, por parte de determinada organização ou grupo, de procedimentos e arranjos estruturais implementados por outras organizações ou grupos, com a finalidade de reduzir a incerteza ocasionada por problemas tecnológicos, objetivos conflitantes e exigências institucionais.

Por fim, em relação ao isomorfismo normativo, Dimaggio e Powell (1983) afirmam que este se refere à ligação das organizações com a profissionalização. As organizações que atuam no mercado enfrentam pressões constantes pelo aumento da eficiência competitiva e, por isso, o isomorfismo normativo encoraja a homogeneização das organizações, com o objetivo de assegurar o fornecimento dos mesmos benefícios e serviços para todos os competidores.

O único elemento que estava alinhado com a definição constitutiva do isomorfismo normativo foi coletado a partir do depoimento do servidor E1, que explicou que em experiência anterior como diretor de um campus pertencente a outra rede, existia uma associação dos dirigentes dos Institutos Federais do Rio Grande do Sul (RS). Conforme o entrevistado, as emendas parlamentares eram solicitadas de maneira coletiva, não beneficiando apenas uma unidade, mas distribuindo o recurso entre todas as unidades participantes. Associações criadas com o objetivo de defender interesses comuns de um grupo caracteriza o isomorfismo normativo.

O isomorfismo normativo está associado com profissionalização, ou seja, com a luta coletiva dos membros de uma ocupação para definir as condições e os métodos do seu trabalho, para controlar a produção e para estabelecer uma base cognitiva e legítima para sua autonomia ocupacional. As associações profissionais constituem veículo para definição e promulgação de regras sobre organizações e comportamento profissional (Souza, Claro e Tinoco, 2012).

Cabe destacar que, embora as três dimensões do isomorfismo, originalmente propostas por Dimaggio e Powell (1983), sejam amplamente aceitas e disseminadas no meio acadêmico, as mesmas não estão imunes a críticas. Críticas acerca do isomorfismo proposto Dimaggio e Powell (1983), principalmente voltadas ao isomorfismo mimético, aduzem que, na perspectiva proposta, de um lado há uma força técnica que é um processo de tomada de decisão racional e de outro lado existe a irracionalidade de imitar um procedimento que se mostrou adequado (Lounsbury, 2008).

Geralmente a ênfase das pesquisas acaba centrada no processo mimético ao invés de valorizar a racionalidade do ator na busca por soluções. Lounsbury (2008) afirma que o isomorfismo mimético acaba figurando como um processo irracional por parte dos autores, que se limita a reproduzir técnicas que 
se mostraram adequadas em outras organizações. A clareza dessas limitações permite a possibilidade de pesquisas futuras que possam complementar os resultados encontrados.

\section{CONCLUSÃO}

A maneira como o orçamento público é planejado atinge diretamente diversas esferas e instituições do Brasil, visto que se concentra na busca da satisfação das necessidades coletivas. Sob uma abordagem interpretativista, nesta pesquisa, o orçamento público posiciona-se em um contexto socioinstitucional, permitindo uma abordagem que vai além daquela que o concebe apenas como um instrumento técnico.

O objetivo desta pesquisa foi analisar o processo orçamentário de uma instituição pública de ensino sob a ótica do isomorfismo segundo Dimaggio e Powell (1983). Os resultados mostram que o processo orçamentário objeto deste estudo é explicado pelos três tipos de isomorfismo em conformidade com a nova sociologia institucional. Observou-se que os três tipos de isomorfismo atuam simultaneamente, norteando o processo orçamentário.

Portanto, o processo orçamentário dos campi pesquisados assemelham-se entre si. Há influência dos três tipos de isomorfismo, com destaque para o isomorfismo coercitivo. $\mathrm{O}$ isomorfismo normativo é o menos explorado. Considerando a perspectiva da Teoria Institucional, os resultados encontrados mostram que o processo orçamentário constitui-se como um elemento do contexto socioinstitucional. O contexto socioinstitucional exerce influência e também é influenciado pelo processo orçamentário.

O fato de o processo orçamentário receber influência do isomorfismo revela que há oportunidades para os gestores obterem ganhos de eficiência. Essa compreensão permite aos gestores configurar um ambiente propício para a implementação ou aprimoramento das práticas orçamentárias. A criação de um ambiente favorável para a troca de experiências, observação e compartilhamento de práticas bem sucedidas, união de dirigentes para a busca de objetivos comuns, participação ativa na revisão e proposição de novas normativas, são exemplos de ações que permitem o aprimoramento da gestão pública.

Sugere-se a elaboração de pesquisas futuras, com foco nos atores e nas práticas, que também busquem explicações para práticas orçamentárias entre organizações, mas com a ênfase voltada para a racionalidade do ator no desenvolvimento de práticas de gestão. Outras possibilidades de estudos futuros envolvem a reaplicação desta pesquisa em outras instituições públicas, sejam elas institutos ou universidades federais, bem como instituições de ensino comunitárias ou privadas.

\section{Agradecimientos}

O presente trabalho foi realizado com apoio daCoordenação de Aperfeiçoamento de Pessoal de Nível Superior - Brasil(CAPES) - Código de Financiamento 001

\section{REFERÊNCIAS}

Abdel-Kader, M., Luther, R. (2006). IFAC's conception of the evolution of management accounting. Advances in management accounting, 15, 229-247.

Baêta, O. V., Sousa, J. S., Antonialli, L. M., Cappelle, M. C. A. (2014). Plano de Gestão nas Universidades Federais Brasileiras: sob a ótica do Institucionalismo Sociológico. Business Management Review, 4, 245-256.

Bardin, L. (2009). Análise de conteúdo. Lisboa: Edições 70.

Burns, J., Scapens, R. W. (2000). Conceptualizing management accounting change: an institutional framework. Management Accounting Research, 11, 3-25.

Collins, R. (1979). The credential society. New York: Academic Press. 
Coser, C., Machado-da-Silva, C. (2004). Organização Focal e Relações de Poder em um Campo Organizacional. Anais do Enanpad, Curitiba, Paraná, Brasil, 28.

Covaleski, M. A., Evans, III, J. H., Luft, J. L., Shields, M. D. (2003). Budgeting research: three theoretical perspectives and criteria for selective integration. Journal of Management Accounting Research, 15(1), 3-49.

Covaleski, M. A., Dirsmith, M. W., Samuel, S. (1996). Managerial accounting research: the contributions of organizational and sociological theories. Journal of Management Accounting Research, 8, 1-35.

Cruz, F. (2001). Comentários à Lei 4.320. (2 ed.). São Paulo: Atlas.

Dimaggio, P. J., Powell, W. W. (1983). The iron cage revisited: institutional isomorphism and collective rationality in organizational fields. American Sociological Review, 48(2), 147-160.

Diniz, J. M. A., Mesquita, N., Tassigny, M., Assis, F. (2015). Encontros de Iniciação Científica em Administração e o processo de Institucionalização de uma Instituição de Ensino Superior. Revista UNIABEU, 8, 109-124.

Eisenhardt, K. M. (1989). Building theories from case study research. The Academy of Management Review, 14(4), 532-550.

Fonseca, V. S., Machado-da-Silva, C. L. (2002). Conversações entre abordagens da estratégia em organizações: escolha estratégica, cognição e instituição. Organizaçôes \& Sociedade, 9(25), 93-109.

Freitas, C. A. S. (2005). Aprendizagem, isomorfismo e institucionalizaçâo: o caso da atividade de auditoria operacional no Tribunal de Contas da União. Dissertação de Mestrado, Programa de Pós-Graduação em Administração da UnB, Brasília, DF, Brasil.

Giacomoni, J. (2005). Orçamento público (13. ed.). São Paulo: Atlas.

Guerreiro, R., Pereira, C. A., Frezatti, F. (2006). Evaluating management accounting change according to the institutional theory approach: a case study of a Brazilian bank. Journal of Accounting \& Organizational Change, 2(3), 196-228.

Hawley, A. (1968). Human ecology. In D. L. SILLS (ed.). International Encyclopedia of the Social Sciences (pp. 328-337). NewYork: Macmillan.

Larson, M. S. (1977). The rise of professionalism: a sociological analysis. Berkeley: University of California Press.

Libby, T., Lindsay, R. M. (2010). Beyond Budgeting or Budgeting Reconsidered? A Survey of North-American Budgeting Practice. Management Accounting Review, 2(1), 56-75.

Loundsbury, M. (2008). Institutional rationality and practice variation: New directions in the institutional analysis of practice. Accounting, Organizations and Society, 33, 349-361.

Luft, J., Shields, M. D. (2003). Mapping management accounting: graphics and guidelines for theory-consistent empirical research. Accounting, Organization and Society. 28(2-3), 169-249.

Machado-da-Silva, C. L., Fonseca, V. S. (1993). Estruturação da Estrutura Organizacional: O Caso de Uma Empresa Familiar. Organizaçôes \& Sociedade, 1(1), $42-71$.

Machado-da-Silva, C. L., Vizeu, F. (2007). Análise Institucional de Práticas Formais de Estratégia. RAE - Revista de Administração de Empresas, 47(4), 89-100.

Machado-da-Silva, C., Barbosa, S. L. (2002). Estratégia, fatores de competitividade e contexto de referência das organizações: uma análise arquetípica. Revista de Administração Contemporânea, 6(3), 7-32.

Martins, G. A., Theóphilo, C. R. (2007). Metodologia da investigação cientificca para ciências sociais aplicadas. São Paulo: Atlas.

Meyer, J. W., Rowan, B. (1977). Institutionalized organizations: formal structure as myth and ceremony. The American Journal of Sociology, 83(2), 340-363.

Ostergren, K., Stensaker, I. (2011). Management control without budgets: A field study of "Beyond Budgeting" in practice. European Accounting Review, 20(1), 149-181.

Pacheco, F. L. (2002). O Isomorfismo Institucional nos Teatros da Região Metropolitana de Recife. Anais do Encontro Nacional de Estudos Organizacionais, Recife, Pernambuco, Brasil, 2. 
Pereira, C. A., Guerreiro, R. (2005). Avaliação do Processo de Mudança da Contabilidade Gerencial sob o Enfoque da Teoria Institucional: O Caso do Banco do Brasil. Anais do Encontro Enanpad, 2005. Rio de Janeiro, Rio de Janeiro, Brasil, 29.

Queiroz, T. L. A., Cavalcante, P. (2011). As contribuições do software Atlas Ti para análise qualitativa de relatos de experiência escritos. Anais do Congresso Nacional de Educação e Seminário Internacional de representaçóes sociais, subjetividade e educação, Curitiba, Paraná, Brasil, 10.

Quirino, S. R. (2011). Orçamento público como fonte de estudos educacionais. Revista de Financiamento da Educação - Fineduca, 1(9), 1-18.

Ribeiro, J. A., Scapens, R. W. (2006). Institutional theories in management accounting change: contributions, issues and paths for development. Qualitative Research in Accounting \& Management, 3(2), 94-111.

Ryan, B., Scapens, R. W., Theobald, M. (2002). Research method methodology in finance e accounting. London: Cengage Learning.

Saviani, D. (2015). História, educação e transformação: tendências e perspectivas para a educação pública no Brasil. In J. C. Lombardi \& D. Saviani (Orgs.). História, educação e transformação. Campinas: Autores Associados.

Scapens, R. W. (1990). Researching management accounting practice: the role of case study methods. British Accounting Review, 22, 259-281.

Scott, W. R. (1995). Institutions and Organizations. London: Sage.

Silva, H. S., Teixeira, M. G. (2016). A influência dos atores na institucionalização do meio ambiente e do desenvolvimento regional em uma instituição federal de educação profissional e tecnológica. Revista Brasileira de Gestão e Desenvolvimento Regional, 12(3), 346-370.

Sivabalan, P., Booth, P., Malmi, T, Brown, D. A. (2009). An exploratory study of operational reasons to budget. Accounting and Finance, 49(4), 849-871.

Souza, W., Claro, J. A. C., Tinoco, J. E. (2012). Processo de Institucionalização: o Caso da Universidade Federal do Tocantins. Revista de Administração e Negócios da Amazônia, 4(2), 78-88.

Uyar, A, Bilgin, N. (2011). Budgeting practices in the Turkish hospitality industry: an exploratory survey in the Antalya region. International Journal of Hospitality Management, 30(2), 398-408.

Xerez, S. (2013). A evolução do orçamento público e seus instrumentos de planejamento. Revista Cientifica Semana Acadêmica, 1(43), 1-19.

Yin, R. K. (2016). Pesquisa qualitativa do início ao fim. Porto Alegre: Penso.

Zucker, L. (1977). The role of institutionalization in cultural persistence. American Sociological Review, 41(5), 726-743.

\section{BY-NC-ND}

